Sharif University of Technology
Scientia Iranica

\title{
Design and optimization of a large-scale permanent magnet synchronous generator
}

\author{
M. Alemi-Rostami ${ }^{\mathrm{a}, *}$, G. Rezazadeh ${ }^{\mathrm{b}}$, R. Alipour-Sarabi ${ }^{\mathrm{b}}$, and F. Tahami ${ }^{\mathrm{b}}$ \\ a. Department of Electrical Engineering, Aerospace Research Institute (ARI) of Ministry of Science, Research and Technology, \\ Tehran, Iran. \\ b. Department of Electrical Engineering, Sharif University of Technology, Tehran, Iran.
}

Received 16 May 2019; received in revised form 26 June 2019; accepted 16 September 2019

KEYWORDS
Direct-drive
permanent magnet
synchronous
generator;
Design and
optimization;
Winding function
method;
Performance
calculation;
Voltage THD
calculation;
Optimum skew angle.

\section{KEYWORDS}

permanent magnet

synchronous

optimization;

Winding function

method;

Performance

Optimum skew angle.

\begin{abstract}
Direct-drive permanent magnet synchronous generators enjoy numerous advantages including improved reliability, low maintenance, long life, and developed performance characteristics. In recent years, many researchers have worked on these generators to enhance their performance, especially for the wind turbine application. The focus of this paper is on the development of a step-by-step method for the design of a permanent magnet synchronous generator. Then, the winding function method is used to model the generator and calculate its output characteristics analytically. The analytical results of the designed generator are validated using Finite Element Analysis (FEA) and it is demonstrated that the obtained results from both methods are in great agreement with the experimental measurements of the Northern Power direct-drive generator. The sensitivity analysis and optimization procedure based on genetic algorithm are employed to design an optimum generator. The optimization goal is obtaining higher efficiency and power factor with lower voltage regulation and required permanent magnet volume compared to the initial design. In addition, the calculation of the voltage Total Harmonic Distortion (THD) is presented and the optimum skew angle for the optimum generator is computed to reduce the voltage THD.
\end{abstract}

(C) 2022 Sharif University of Technology. All rights reserved.

\section{Introduction}

In recent years, Direct-Drive Permanent Magnet Synchronous Generators (DD-PMSGs) have been widely used in large-scale wind turbines because of their improved reliability, low maintenance, long service life, and upgraded performance characteristics that are required in wind power generators [1-3]. However,

*. Corresponding author.

E-mail addresses: alemi@ari.ac.ir (M. Alemi-Rostami);

s.g.rezazadeh.s@gmail.com (G.Rezazadeh);

Ramin.alipoursarabi@gmail.com (R. Alipour-Sarabi);

Tahami@sharif.edu (F. Tahami)

doi: $10.24200 /$ sci. 2019.53569 .3314 the main drawbacks of these generators are large dimensions and consequently, the greater weight and material costs, especially for the PMs. It is clear that the optimal design must be oriented to minimize the required $\mathrm{PM}$ volume without sacrificing the generator performance [4].

The previous research on the PMSGs can be categorized into three specific subjects:

1. Design, Optimization, and Structure Improvement: A direct-driven permanent magnet synchronous generator was designed using Finite Element Method (FEM) in [5], and good agreement between the simulation and the experimental results was found. In [6], a multi-objective optimization 
function was employed to design a PMSG with maximum annual energy production and minimum permanent magnet volume. The direct-drive PM generator design can be optimized to achieve different purposes such as minimal generator active material cost [7], minimal power loss cost (considering the annual wind profile) [8], and maximal air gap apparent power (under tangential stress constraint) [2]. In addition, PMSG can be designed and utilized for specific applications such as telecom tower wind turbine [9] and energy recovery system [4]. In recent years, the design of multiphase PMSG has been developed and these types of generators are promising [10]. Considering the large number of expensive materials required to be used in the PMSGs, estimating the lifetime cost of the generator is worthwhile for design optimization $[11,12]$. In [13], the authors presented an optimal design of high-speed slot-less PMSG with surfacemounted magnets and Soft Magnetic Composite (SMC) stator yoke. The effect of the electrical steel properties on the temperature distribution in PMSG was addressed in [14]. Some promising research was done in order to reduce the weight and temperature of PMSG stator [3,15] and to increase the rotor speed [16]. In [17], the authors used a multi-physic model comprising six sub-models, i.e., electrical, magnetic, thermal, mechanical, geometrical, and economical, to design an optimum $55 \mathrm{~kW}$ PMSG. Several optimization methods exist in the literature for designing PM synchronous machines such as sequential stage strategy [18], interactive multi-objective [19], Monte Carlo [20], and multiobjective genetic algorithm [21].

2. Analysis and Modeling: There are so many papers discussing the analysis and modeling of PMSGs and they are almost based on some excellent pioneering works in 80's [22,23]. An analytical model for PMSG can be derived using electromagnetic equations. To solve these non-linear equations, a transformation is adopted to simplify the nonlinearity problem; otherwise, FEA may be used $[24,25]$. Subsequently, deriving an equivalent circuit and estimating its parameter seem necessary to represent machine performance straightforwardly [26]. However, in many applications such as small wind power systems, a simple equivalent circuit model consisting of internal voltages and phase inductances is used to simplify the wind power system analysis [27].

3. Control and Performance Enhancement: After designing and modeling the PMSG, choosing a worthwhile control strategy and employing an optimized controller is the next fundamental step to enhance the machine performance $[28,29]$. In the control system research, another challenge is providing an observer system for the sensor-less control methods [30].

This paper mainly presents the designing procedure of the direct-drive permanent magnet synchronous generator in large size, which is excellent for the wind turbine application. In this respect, an optimum 1.5 MW PMSG is designed through some steps as the initial design. The performance of the designed generator is measured using the presented analytical model based on the winding function analysis [31]. The analytical results are validated with the experimental results of the Northern Power direct-drive generator from [32]. After that, PMSG's dimensions are optimized using Genetic Algorithm (GA) [33] to reduce the required PM volume and voltage regulation and to enhance the efficiency and power factor compared to the initial design (Northern Power generator). In addition, choosing an appropriate skew angle for the optimum generator is studied based on the winding function analysis to obtain the lowest voltage THD with respect to the voltage drop limitation. In the last step, 2D FEA is used to verify all the analytical results for the performance of the initial and optimum designs. The simulation results for the initial design are compatible with the experimental results of the Northern Power generator.

\section{Design method}

The design process of an electrical machine comprises four basic parts: input variables, assumptions, output variables, and design procedure. These parts are defined in Figure 1, where the design method is de-

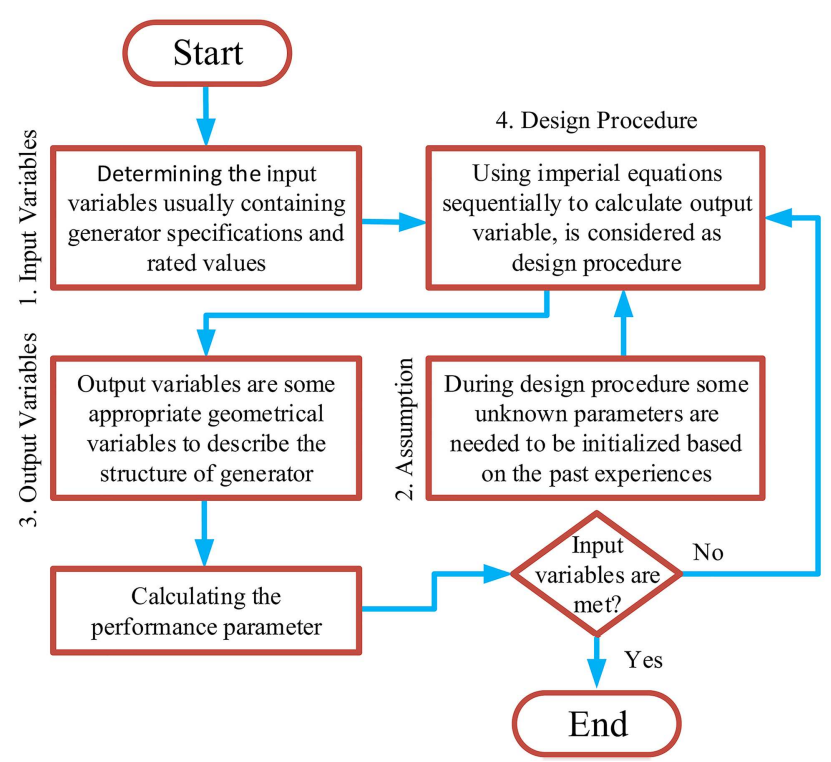

Figure 1. Design algorithm of the permanent magnet synchronous generator. 
Table 1. Input variables and assumption parameters of PMSG design.

\begin{tabular}{clccc}
\hline & \multicolumn{1}{c}{ Quantity } & Symbol & Unit & Value \\
\hline \multirow{4}{*}{$\begin{array}{c}\text { Nesign input } \\
\text { variables }\end{array}$} & $P_{n}$ & $\mathrm{~kW}$ & 1500 \\
& Rotor mechanical speed & $\omega_{m}$ & $\mathrm{RPM}$ & 19.65 \\
& Phase number & $m$ & - & 3 \\
& Number of pole pairs & $p$ & - & 28 \\
& Generator output frequency & $f$ & $\mathrm{~Hz}$ & 9.14 \\
& No-load line to line voltage & $V_{L-L}$ & $\mathrm{~V}$ & 725 \\
& & & & \\
& Gap average flux density & $B_{g}$ & $\mathrm{~T}$ & 0.7 \\
& Current density & $J_{s}$ & $\mathrm{~A} / \mathrm{mm}^{2}$ & 4.6 \\
& Winding factor & $k_{w}$ & - & 0.95 \\
& Copper fill factor & $k_{c u}$ & - & 0.5 \\
& Length to diameter ratio & $L / D$ & - & 0.4 \\
& Slot per pole per phase & $q$ & - & 2 \\
Specific electric loading & $a c$ & $\mathrm{~A} / \mathrm{m}^{2}$ & 50000 \\
Design assumption & Specific magnetic loading & $B_{a v}$ & $\mathrm{~Wb} / \mathrm{m}^{2}$ & 0.7 \\
& Max. of teeth flux density & $B_{t}$ & $\mathrm{~T}$ & 1.5 \\
& Max of yoke flux density & $B_{y}$ & $\mathrm{~T}$ & 1.3 \\
& PM Utilization coefficient & $c v$ & - & 0.55 \\
& Remnant flux density of PM & $B_{r}$ & $\mathrm{~T}$ & 1 \\
& Coercive force of PM & $H_{c}$ & $\mathrm{AT} / \mathrm{m}$ & 700000 \\
\hline
\end{tabular}

scribed using a graphical algorithm. To design the case study PMSG, the first two basic parts including input variables and assumptions are presented in Table 1. Figure 2 shows the third part (output variables) of the design process for the case study PMSG.

In the last part of the PMSG design process called design procedure, the PM synchronous generator is designed through definite sequential steps and the result of each step is necessary for the next step. These steps will continue until all the output variables are found. To describe the design procedure of the casestudy PMSG, the design algorithm is presented in Figure 3. In the first step, the main characteristics of PMSG should be determined; then, the stator dimensional parameters are calculated. To ensure that no saturation occurs in the core, mechanical air gap length, rotor dimensional parameters, and performance indicating parameters are calculated in the next steps of the proposed algorithm. Finally, the output power and voltage should be examined to ensure that the PMSG output characteristics are acceptable. Some well-known equations used in the design algorithm are presented in detail as follows.

\subsection{Stator main dimensions}

This equation shows how the stator main dimensions such as inner diameter and length are related to the generator nominal power. There are two coefficients,

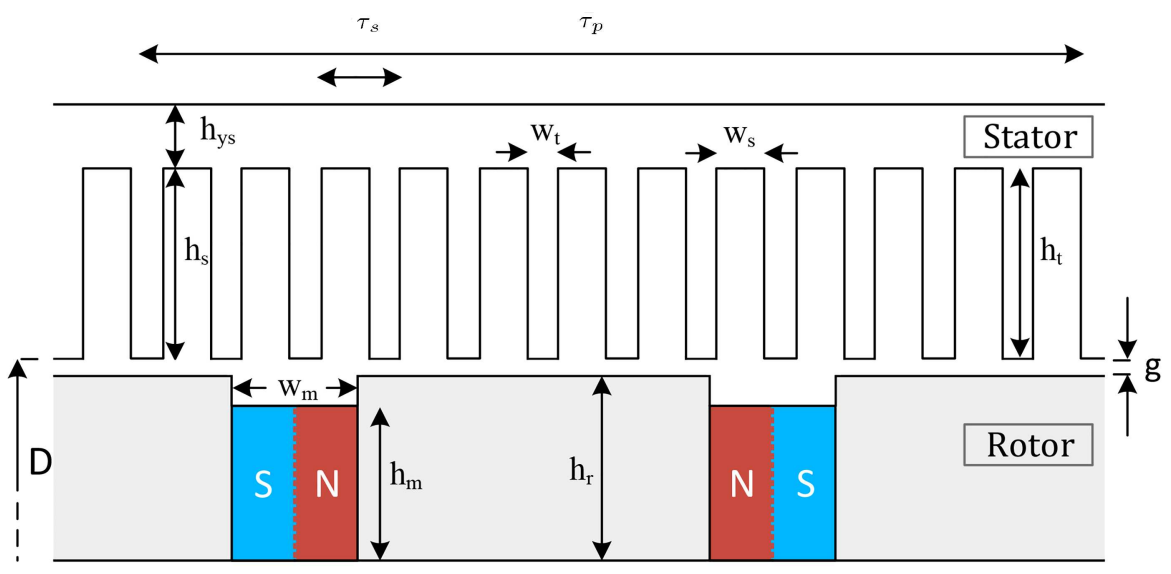

Figure 2. Output variables of PMSG design (dimensional parameters). 


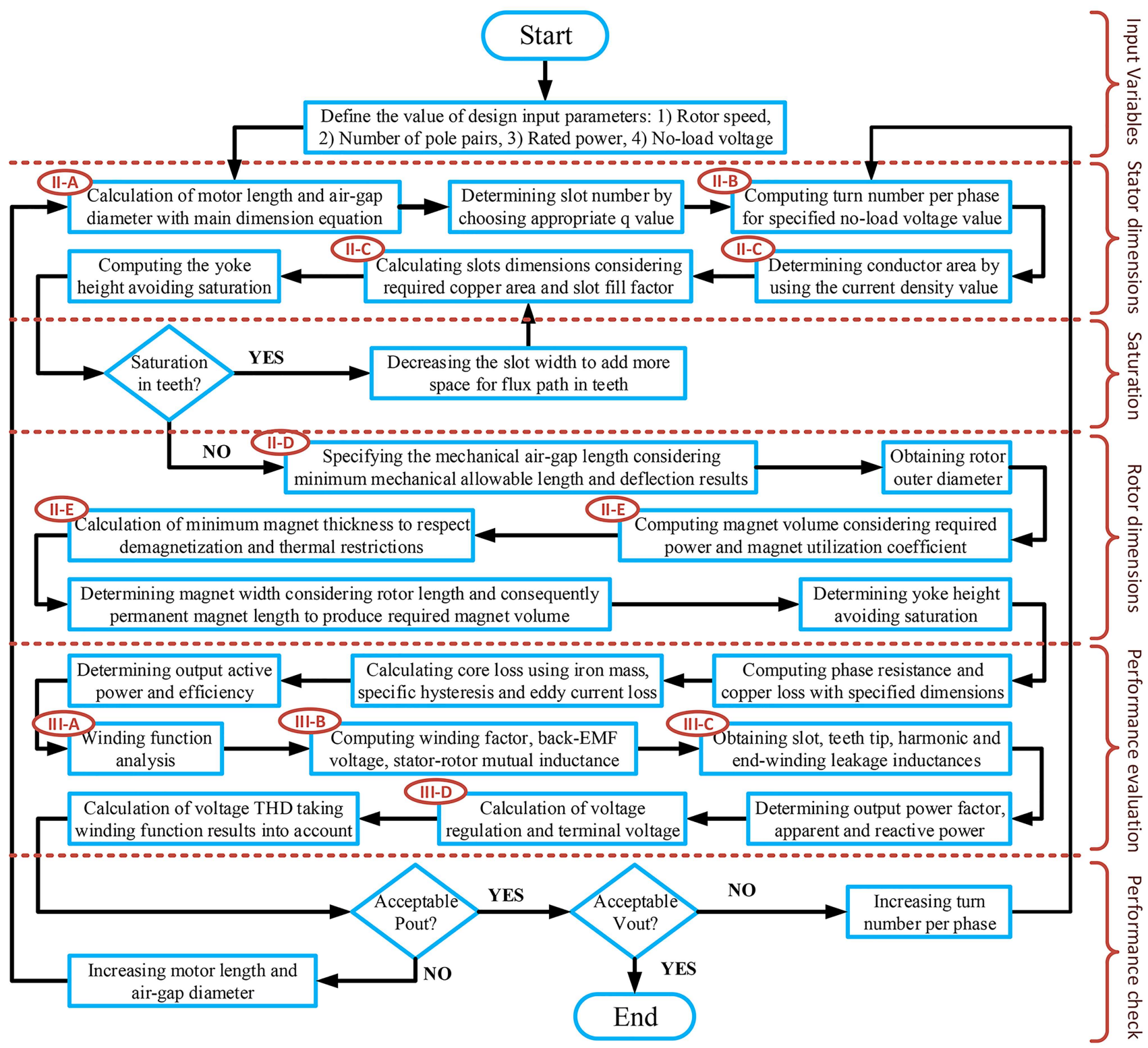

Figure 3. An algorithm to describe the design procedure part of the permanent magnet synchronous generator. The detailed discussion is addressed for each block.

specific electrical loading, and specific magnetic loading in the equation and they demonstrate how well the generator is loaded [2]:

$$
S=1.11 \times 10^{-3} \times \pi^{2}\left(K_{w} B_{a v} a c\right) D_{i}^{2} L n_{s}
$$

where $n_{s}$ is the generator synchronous speed in radian per second. Other parameters incorporated into the main dimensions equation are defined in Table 1.

\subsection{Stator $E M F$}

Considering the distributed winding of the stator, the induced voltage per phase is [2]:

$$
E_{p}=\frac{2 \pi}{\sqrt{2}} N_{p h} K_{w} f\left(\frac{\pi B_{g} D_{i} L}{2 p}\right),
$$

where the per phase turn number $\left(N_{p h}\right)$ plays the main role in adjusting the phase-induced EMF.

\subsection{Stator slot dimensions}

Two restrictions should be respected in this sizing. First, the slot should have enough area $\left(A_{\text {slot }}\right)$ to settle conductors considering the slot copper fill factor and the conductor area $\left(A_{\text {con }}\right)[34]$ :

$$
A_{\text {slot }}=\frac{A_{c o n} N_{p h}}{p q k_{c u}}, \quad A_{c o n}=\frac{S}{\sqrt{3} \times V_{L-L} J_{s}} .
$$

Second, the tooth should be wider than the specified minimum width $\left(\omega_{t \text { min }}\right)$ to avoid the tooth saturation occurrence [34]:

$$
\omega_{t \min }=\left(\pi D_{i} B_{g}\right) /\left(S_{s} B_{t}\right)
$$


where $S_{s}$ is the stator slot number.

\subsection{Air gap mechanical length}

The generator performance highly depends on the length of the air gap. The air gap should be small to minimize the dimension/size of the required permanent magnets. The mechanical stiffness and the thermal expansion of the generator limit the minimum air gap length. In this paper, the minimum air gap length is assumed to be $4 \mathrm{~mm}$ [32] and the minimum utilized air gap length is $4.7 \mathrm{~mm}$ considering the results of deflection analysis from [32].

\subsection{Permanent magnet sizing}

The permanent magnet volume used in the rotor structure depends on the quality of PM material and the machine air gap power $\left(P_{a g}\right)$. PM quality can be described by its maximum energy content, which is determined by the remanent flux density and coercive force of PM.

$$
V_{m}=c v \frac{P_{a g}}{B_{r} H_{c} f}
$$

where $c v$ is a constant value determined by the magnet utilization coefficient, generator overload capacity, and rotor structure. The utilized PM in this paper is $\mathrm{NdFeB}$ type with the maximum allowable temperature of $155^{\circ} \mathrm{C}$. To produce a certain PM flux density in the air gap $\left(B_{g P M}\right)$, the PM width is supposed to be greater than $\omega_{P M 1}[35]$ :

$$
\omega_{P M 1}=\frac{g B_{g P M} k_{s a t}}{\mu_{0} H_{c}\left(1-\frac{B_{g P M}}{B_{r}} k_{s a t}\right)},
$$

where $k_{\text {sat }}$ is the saturation factor. The minimum PM width to avoid demagnetization under short overload is $[35]$ :

$$
\omega_{P M 2}=\frac{a c \cdot k_{1} k_{J} \pi D_{i}}{2 p H_{c}},
$$

where $k_{J}$ is the stator MMF distribution factor and $k_{l}$ is the maximum overload factor. Because both of these limitations should be met, the highest PM width between $\omega_{P M 1}$ and $\omega_{P M 2}$ is chosen for the required PM width.

\section{Performance analysis}

It is necessary to analyze the designed PMSG performance mathematically. The PMSG performance parameters are calculated through the steps given in Figure 3. The first step is to calculate the PMSG losses such as copper, core, magnet, additional friction, and windage losses. This calculation requires some wellknown equations, which are available in $[36,37]$. Other steps are defined as follows.

\subsection{Winding function analysis}

The winding function is the cumulative sum of the turn numbers of a phase winding along the stator periphery. The total winding function is the sum of all phase winding functions taking their spatial phase shift into account $[31,38]$ :

$$
N_{t o t}(\theta)=\sum_{i=1}^{m} N_{i}(\theta) \cdot \cos \left(\theta_{i}\right)
$$

where $\theta$ is the spatial phase shift between phases, $N_{i}$ is the winding function value for phase $i$, and $m$ is the number of stator phases.

\subsection{Winding factor and stator-rotor mutual inductance}

The winding factor for the $h$ th harmonic can be determined using FFT results of the total winding function $[31,38]$ :

$$
k_{W-h}=\frac{\pi p^{2} q m h N_{t o t-h}}{N_{p h} S_{s}} .
$$

The stator-rotor mutual inductance can be described as [38]:

$$
L_{a}=\frac{m \mu_{0} D_{i} L N_{t o t}^{2}}{\pi p^{2} g}
$$

\subsection{Leakage inductances}

To calculate the harmonic leakage inductance $\left(L_{h}\right)$, an alternative method is to use of finite harmonics approach (based on Görges polygon diagram analysis) $[31,38]$ :

$L_{h}=L_{a}\left(\frac{R_{g}^{2}}{R_{P}^{2}}-1\right), \quad R_{P}=\frac{2 m f N_{t o t-1}}{p} I_{1}$

$R_{g}=I_{1} \sqrt{\frac{1}{S_{s}} \sum_{h=1}^{S_{s}}\left[\widehat{N}_{t o t-h}^{2}\left(\omega t=0^{o}\right)+\widehat{N}_{t o t-h}^{2}\left(\omega t=90^{\circ}\right)\right]}$

where $R_{p}$ is the radius of gyration of fundamental harmonic in Görges polygon, $R_{g}$ the radius of gyration in Görges diagram, and $I_{1}$ the amplitude of the stator current.

The slot, tooth tip, and end winding leakage inductance are three other parts of the stator leakage inductance. Several expressions exist in the literature that compute these leakage inductances [31]:

$$
L_{l}=2 p q \mu_{0} L\left(\frac{2 h_{s}}{3 \omega_{s}}+\frac{g}{\omega_{s}+g}\right)+2.4 \mu_{0} l_{e w} n_{c / p h} N_{c}^{2} k_{w}^{2}
$$

where $l_{e w}$ is the average length of end-winding, $n_{c / p h}$ the coil number per phase, and $N_{c}$ the conductor number per coil.

\subsection{Voltage regulation}

In the nominal condition, the output voltage is as follows [36]: 


$$
\begin{aligned}
& V_{\text {out }}=\sqrt{E_{p}^{2}-V_{\text {drop }}^{2} \sin ^{2}\left(\theta_{\text {drop }}\right)}-V_{\text {drop }} \cos \left(\theta_{\text {drop }}\right), \\
& V_{\text {drop }}=I_{1} \times \sqrt{R_{s}^{2}+\left(2 \pi f\left(L_{a}+L_{h}+L_{l}\right)\right)^{2}}, \\
& \theta_{\text {drop }}=\tan ^{-1}\left(\frac{2 \pi f \times\left(L_{a}+L_{h}+L_{l}\right)}{R_{s}}\right)-\phi,
\end{aligned}
$$

where $V_{\text {drop }}$ and $\theta_{\text {drop }}$ are the amplitude and the phasor of the voltage drop across the stator impedance, respectively. The voltage regulation is defined as follows:

$$
V_{\text {reg }}=\left(E_{p}-V_{\text {out }}\right) / V_{\text {out }} \text {. }
$$

The calculation and FEA simulation results for the initial design PMSG are reported in Table 2 compared to the experimental results from [32]. It is clear that the initial design results well in agreement with the experimental measurements.

\section{Sensitivity analysis}

In order to design the optimum PMSG, it is necessary to study the effect of each parameter on the PMSG performance. The effects of stator, rotor, and PM dimensions on the power factor, efficiency, and voltage regulation are studied. The results are briefly presented in Figure 4 to Figure 6. As can be seen, every single physical parameter affects one or more performanceassociated parameters and these changes may occur in different directions. In other words, changing a design parameter can improve one performance parameter but worsen another. The sensitivity analysis results can be described as follows:

- In a determined nominal power, use of a larger generator diameter and length results in lower voltage regulation (Figure 4), because the nominal voltage is enhanced, while the nominal current is reduced. However, using larger dimensions for the generator means more required PM volume;

- According to Figure 5, increasing the slot dimensions enhances the PMSG efficiency by increasing the copper-filled area in each slot, which reduces the copper loss. On the other hand, this alternation heightens the slot leakage inductance value and consequently, decreases the PMSG power factor;

- Figure 6 shows the variation of the PM volume and power factor in terms of PM dimensions. The obvi-

\begin{tabular}{|c|c|c|c|c|c|}
\hline & Quantity & Unit & Calculation & Simulation & Measured [32] \\
\hline \multirow{10}{*}{ 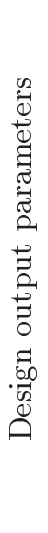 } & Stator inner diameter & $\mathrm{m}$ & 3.48 & 3.48 & 3.48 \\
\hline & Stator length & $\mathrm{m}$ & 0.76 & 0.76 & 0.76 \\
\hline & Stator slot number & - & 336 & 336 & - \\
\hline & Stator slot width & $\mathrm{mm}$ & 11.7 & 11.7 & - \\
\hline & Stator slot height & $\mathrm{mm}$ & 103.8 & 103.8 & - \\
\hline & Turn number per phase & - & 112 & 112 & - \\
\hline & Turn number per slot & - & 2 & 2 & - \\
\hline & Air gap length & $\mathrm{mm}$ & 4.7 & 4.7 & 4.7 \\
\hline & PM width & $\mathrm{mm}$ & 57.8 & 57.8 & - \\
\hline & PM height & $\mathrm{mm}$ & 87.6 & 87.6 & - \\
\hline \multirow{9}{*}{ 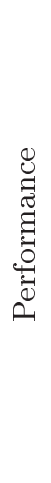 } & Output power & $\mathrm{kW}$ & 1496 & 1503 & 1493 \\
\hline & Total losses & $\mathrm{kW}$ & 121.1 & 118.4 & 124.3 \\
\hline & Efficiency & $\%$ & 92.89 & 93.23 & 92.70 \\
\hline & No-load voltage L-L & $\mathrm{V}$ & 763 & 769.4 & 763.3 \\
\hline & Full-load voltage L-L & $\mathrm{V}$ & 726 & 730.1 & 722.4 \\
\hline & Full-load current & A & 1404 & 1403 & 1404 \\
\hline & No-load voltage THD & $\%$ & 6.24 & 6.02 & 7 \\
\hline & Voltage regulation & $\%$ & 5.73 & 5.38 & 5.65 \\
\hline & Power factor & $\%$ & 85.1 & 84.8 & 85 \\
\hline
\end{tabular}
ous undesired results of increasing PM dimensions include increase in PM volume and, consequently,

Table 2. The calculation and $2 \mathrm{D}$ simulation results of the initial design and the experimental results. 


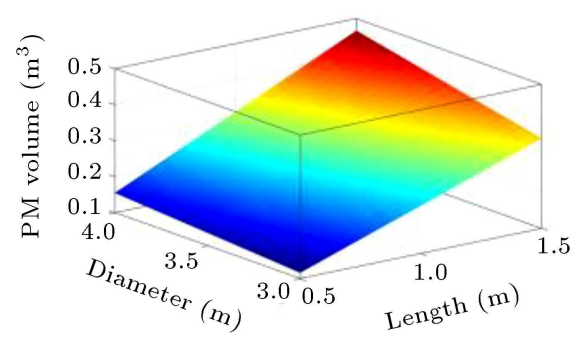

(a)

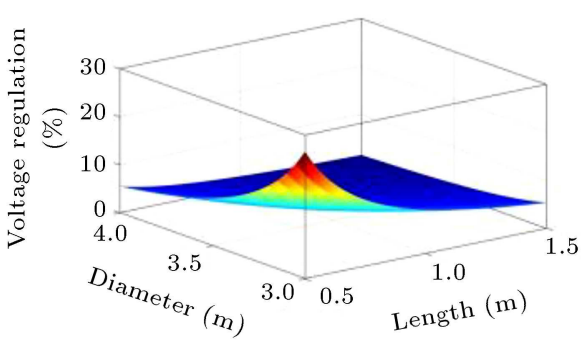

(b)

Figure 4. Output characteristics versus the PMSG length and diameter: (a) Magnet volume and (b) voltage regulation.

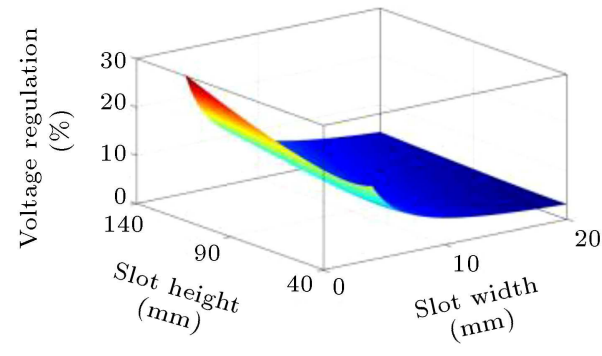

(a)

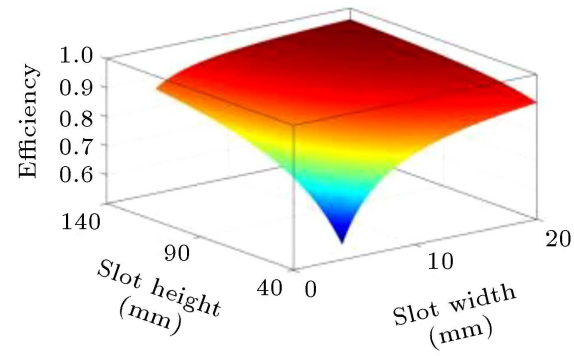

(b)

Figure 5. Output characteristics versus the slot width and height: (a) Voltage regulation and (b) efficiency.

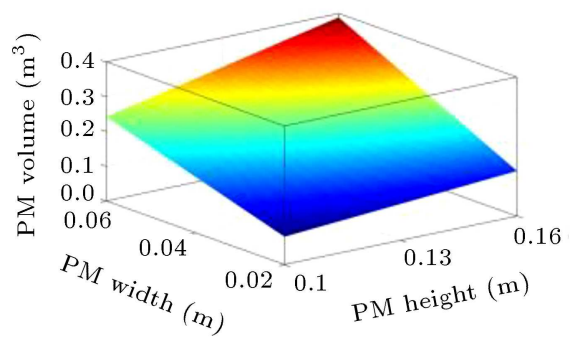

(a)

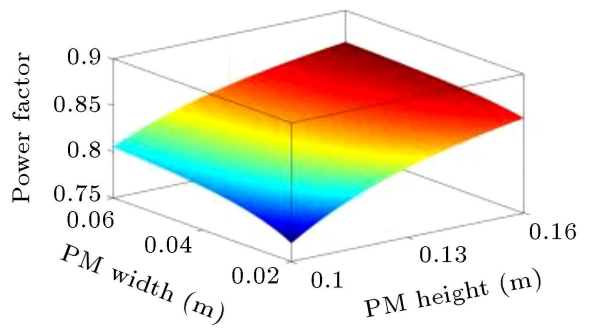

(b)

Figure 6. Output characteristics versus the permanent magnet width and height: (a) Permanent magnet volume and (b) power factor.

PM cost. However, increasing the PM dimensions results in higher power factor.

As is clear, there is no simple solution to find the dimensions of the optimum generator. Thus, a search algorithm needs to be employed to find the best solution, which presents the highest efficiency and power factor as well as the lowest voltage regulation and required PM volume. The significance of defining an appropriate optimization solution is depicted using the sensitivity analysis in this section.

\section{Optimization}

In this section, the optimization problem is defined and solved to calculate the dimensional parameters of the optimum PMSG. The considered optimization problem has three main parts: the objective function, parameter boundaries, and optimization method.

\subsection{Objective function}

Determining performance parameters is the main objective of the optimization which can be described as the product of these parameters. The exponents are used to assign weights to the performance parameters in the objective function. Therefore, the objective function is expressed as follows:

$$
\text { O.F. }=\frac{\eta^{k_{1}} \times P F^{k_{2}}}{V_{r e g}^{k_{3}} \times V_{m}^{k_{4}}},
$$

where $\eta$ is the machine efficiency.

\subsection{Parameters boundary}

Some constraints should be considered for the design variables because of the electromagnetic and mechanical limitations as follows:

1. The maximum flux density of the teeth is the most important constraint and the critical factor to monitor the saturation phenomena; 
Table 3. Boundaries of design parameters based on design constraints.

\begin{tabular}{lccc}
\hline Design parameter & Unit & Min. value & $\begin{array}{c}\text { Max. } \\
\text { value }\end{array}$ \\
\hline Stator tooth flux density & $\mathrm{T}$ & - & 1.7 \\
Stator yoke flux density & $\mathrm{T}$ & - & 1.7 \\
Rotor yoke flux density & $\mathrm{T}$ & - & 1.5 \\
Air gap length & $\mathrm{mm}$ & 4 & 10 \\
Conductor current density & $\mathrm{A} / \mathrm{mm}^{2}$ & 2 & 6 \\
Stator slot width & $\mathrm{mm}$ & 10 & 20 \\
Stator slot height & $\mathrm{mm}$ & 40 & 140 \\
Magnet height & $\mathrm{mm}$ & 60 & 100 \\
Magnet width & $\mathrm{mm}$ & 42 & 70 \\
\hline
\end{tabular}

2. The minimum air gap length is limited because of the mechanical restrictions;

3. In the conductors, maximum current density should be determined to take into the thermal considerations;

4. The minimum slot area should be provided to place the coils in the slots;

5. The permanent magnet thickness should be higher than a specific value to prevent demagnetization;

6. The PM volume should be large enough to produce the desirable output power.

The considered boundaries for design parameters are presented in Table 3 and have been closely related to the assumption parameters introduced previously.

\subsection{Optimization method}

In this paper, the well-known optimization method, Genetic algorithm (GA), is employed. The GA is a meta-heuristic optimization method inspired by the process of natural selection that belongs to the larger class of evolutionary algorithms. The algorithm repeatedly modifies a population of individual solutions by selecting individuals from the current population at each step and using them to produce the next generation. The optimization results are not identical when the algorithm is reemployed. Therefore, the GA should be run several times, 200 times in this paper, to avoid local optimal points. Best of these results is reported as the global optimum point. Figure 7 shows a brief representation of the optimization process [33,39]. Therein, the stop criteria are as follows:

- Number of the generations exceeds 1000 (maximum number of iterations before the algorithm stops);

- The relative average change in the best fitness functions is less than 10-10.

\subsection{Optimization result}

The analytical results of solving the optimization problem are shown in Table 4 considering different weights

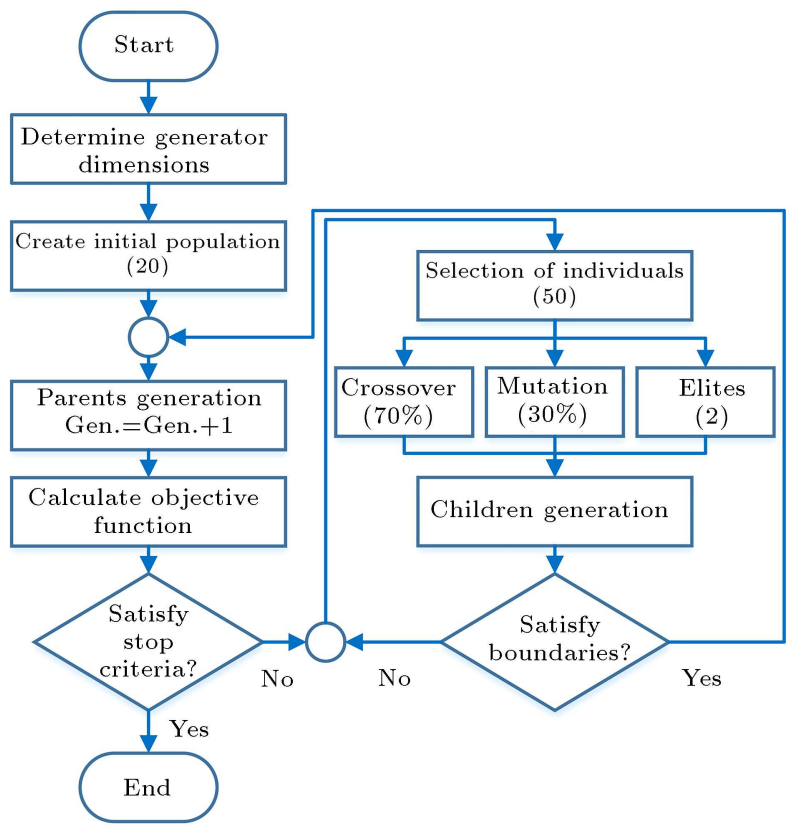

Figure 7. Proposed optimization process based on genetic algorithm.

for the objectives in four cases. In the first case, only efficiency is taken into account and consequently, efficiency increases by more than $2 \%$ compared to the initial design results. In this case, to increase efficiency, the rated voltage and current values are modified significantly. The rated current value decreases which results in less copper loss for this case. This modification can be accepted because the PMSG has a mandatory converter that changes the PMSG output ratings to the required network input ratings. In other words, modifying PMSG ratings only changes the converter rating, which is manageable.

The next three optimal designs for power factor, voltage regulation, and PM volume have the same scenarios as that design for efficiency. In the fifth case, all the aforementioned objectives are considered with the same weights. It should be noted that during these five optimization procedures, the performance characteristics are in acceptable ranges.

\section{Voltage total harmonic distortion}

The EMF value for specific winding can be described as the result of magnetic interaction between the rotor and stator fields. Rotor magnets produce a rotating magnetic field in the air gap and the flux density distribution is shown in Figure 8 . The $h$ th space harmonic of the flux density is:

$$
B_{a g-h}(\theta, t)=B_{h} \cos \left(h \theta+2 \pi f t+\alpha_{h}\right),
$$

where $\alpha_{h}$ is the phase angle of the $h$ th spatial harmonic. The $h$ th harmonic of flux linkage for phase 
Table 4. optimization result for PMSG design.

\begin{tabular}{|c|c|c|c|c|c|c|c|c|c|}
\hline \multirow[b]{2}{*}{ Quantity } & \multirow[b]{2}{*}{$\begin{array}{l}\overrightarrow{0} \\
\dot{0} \\
\text { तू }\end{array}$} & \multicolumn{2}{|c|}{ Initial design } & \multicolumn{5}{|c|}{ Calculation results for different optimization scenarios } & \multirow[b]{2}{*}{$\begin{array}{c}\text { FEA results } \\
\text { of optimum } \\
\text { generator }\end{array}$} \\
\hline & & Calculation & $\begin{array}{c}\text { Measured } \\
\text { from } \\
{[32]}\end{array}$ & $\begin{array}{c}\text { Scenario } 1 \\
k_{1}=1 \\
k_{2}=0 \\
k_{3}=0 \\
k_{4}=0\end{array}$ & $\begin{array}{c}\text { Scenario } 2 \\
k_{1}=0, \\
k_{2}=1 \\
k_{3}=0 \\
k_{4}=0\end{array}$ & $\begin{array}{c}\text { Scenario } 3 \\
k_{1}=0 \\
k_{2}=0 \\
k_{3}=1 \\
k_{4}=0\end{array}$ & $\begin{array}{c}\text { Scenario } 4 \\
k_{1}=0 \\
k_{2}=0 \\
k_{3}=0 \\
k_{4}=1\end{array}$ & $\begin{array}{c}\text { Scenario } 5 \\
k_{1}=1 \\
k_{2}=1 \\
k_{3}=1 \\
k_{4}=1\end{array}$ & \\
\hline Slot width & $\omega_{s}(\mathrm{~mm})$ & 11.7 & - & 12.3 & 12.3 & 12.3 & 10.4 & 11.9 & 11.9 \\
\hline Slot height & $h_{s}(\mathrm{~mm})$ & 103.8 & - & 99.3 & 84.8 & 88.2 & 106.2 & 104.3 & 104.3 \\
\hline Current density & $J_{s}\left(\mathrm{~A} / \mathrm{mm}^{2}\right)$ & 4.6 & - & 3.2 & 3.8 & 3.6 & 6.0 & 4.6 & 4.6 \\
\hline Magnet width & $\omega_{m}(\mathrm{~mm})$ & 57.8 & - & 59.4 & 59.4 & 59.4 & 50.4 & 57.8 & 57.8 \\
\hline Magnet height & $h_{m}(\mathrm{~mm})$ & 87.6 & - & 92.1 & 92.1 & 92.1 & 78.2 & 89.7 & 89.7 \\
\hline Air gap length & $\mathrm{g}(\mathrm{mm})$ & 4.7 & 4.7 & 4.6 & 5.4 & 5.5 & 4.5 & 4.5 & 4.5 \\
\hline Stator length & $\mathrm{L}(\mathrm{m})$ & 0.76 & 0.76 & 1 & 0.98 & 1 & 0.70 & 0.70 & 0.70 \\
\hline $\begin{array}{l}\text { Stator inner } \\
\text { diameter }\end{array}$ & $D_{i}(\mathrm{~m})$ & 3.48 & 3.48 & 3.65 & 3.65 & 3.65 & 3.09 & 3.55 & 3.55 \\
\hline $\begin{array}{l}\text { No-load } \\
\text { voltage L-L }\end{array}$ & $V_{N L-L}(\mathrm{~V})$ & 763 & 763 & 1098 & 1082 & 1099 & 647 & 748 & 756 \\
\hline Full-load current & $I_{F L}(\mathrm{~A})$ & 1404 & 1404 & 918 & 998 & 914 & 1540 & 1330 & 1342 \\
\hline Voltage THD & $V_{T H D}(\%)$ & 6.24 & 7 & 6.46 & 6.46 & 6.46 & 7.59 & 6.53 & 6.28 \\
\hline Output power & $P_{\text {out }}(\mathrm{kW})$ & 1496 & 1493 & 1528 & 1520 & 1524 & 1459 & 1500 & 1519 \\
\hline Efficiency & $\eta(\%)$ & 92.89 & 92.7 & 95.09 & 94.41 & 94.63 & 90.48 & 93.13 & 93.01 \\
\hline Magnet volume & $V_{m}\left(\mathrm{~m}^{3}\right)$ & 0.2047 & - & 0.2991 & 0.2868 & 0.2991 & 0.1467 & 0.1930 & 0.1930 \\
\hline Voltage regulation & $V_{\text {reg }}(\%)$ & 5.73 & 5.65 & 3.48 & 3.12 & 3.09 & 9.51 & 5.65 & 5.43 \\
\hline Power factor & $\operatorname{Pf}(\%)$ & 85.08 & 85 & 87.57 & 87.63 & 87.63 & 84.6 & 86.9 & 86.9 \\
\hline
\end{tabular}

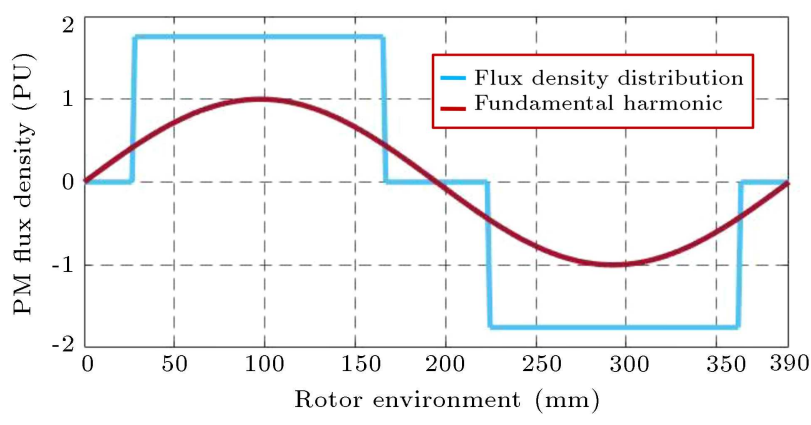

Figure 8. Flux density distribution caused by the rotor magnets (normalized by its fundamental harmonic).

$i$ is described as:

$$
\begin{aligned}
\varphi_{i-h}(t)= & R L \int_{0}^{2 \pi}\left[\sum_{k=1}^{\infty} N_{i-k} \cos \left(k \theta+\beta_{k}\right) \cdot B_{h}\right. \\
& \left.\cos \left(h \theta+2 \pi f t+\alpha_{h}\right) \cdot d \theta\right] .
\end{aligned}
$$

By differentiating the flux linkage of phase $i$, the induced voltage $(\mathrm{EMF})$ yields:

$$
E M F_{h}(t)=\pi R L N_{h} B_{h} \cos \left(2 \pi f t+\alpha_{h}+\beta_{h}\right)
$$

By considering the case of Eq. (18), no-load voltage amplitude for each harmonic is proportional to the product of the rotor flux density and stator winding function amplitudes for that specific harmonic. In other words, the THD of the no-load voltage can be calculated using the FFT results of the rotor flux density distribution and stator winding function.

Skewing the stator poles is a well-known method to decrease the voltage THD [32]. It can also help the machine to work with lower vibration and acoustic noise [40]. The best skew angle and coil-pitch for minimizing the voltage THD can be calculated analytically using the stator winding function and rotor flux density distributions.

The first step is to consider the skew angle $\left(\theta_{\text {skew }}\right)$ in the winding function analysis. It is assumed that there are $x$-layers crossing the machine length axially with a specific shift angle $\left(\theta_{\text {skew }} / x\right)$ between them. The total winding function for each stator phase is the summation of the winding functions of all the $x$-layers. By increasing the $x$ value, calculation results are more precise; however, the computational burden escalates unnecessarily.

By using Eq. (18) and adding the skewing effect to the winding function, the voltage THD can be calculated for different skewing angles (Figure 9). The results show that increasing the skewing angle somehow decreases the voltage THD; however, this improvement reduces the fundamental harmonic of the winding factor and EMF. The EMF drop caused by skewing poles can be described using the skew factor:

$$
k_{\text {skew }}=\frac{\sin \left(p q \theta_{\text {skew }} / 2\right)}{p q \theta_{\text {skew }} / 2} \text {. }
$$

The value of skew factor is shown in Figure 9, in which this factor creates feasible and non-feasible areas 
considering 5\% EMF drop as a critical boundary. The lowest voltage THD in the feasible area is $4.07 \%$ when the skew angle is $2.26^{\circ}$. Figure 10 depicts the winding function of phase $\mathrm{A}$ for skew angles $0^{\circ}$ and $2.26^{\circ}$. It is obvious that the winding function of phase $\mathrm{A}$ has a lower fundamental harmonic and THD value when the slots are skewed.

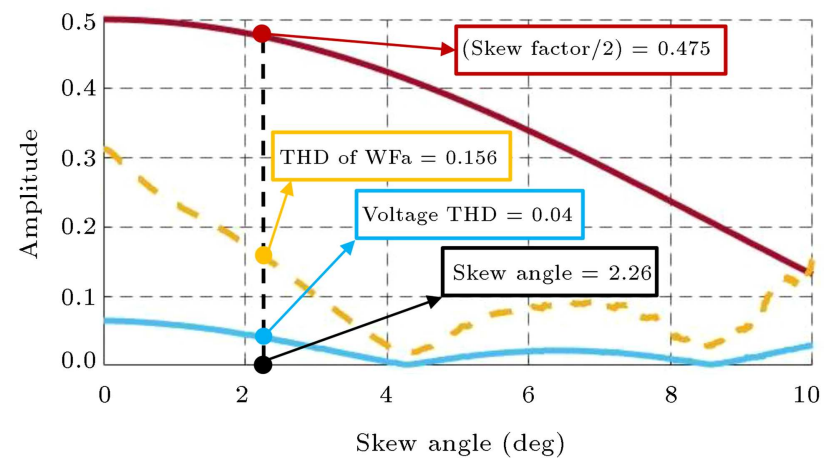

Figure 9. Variation of the voltage THD and the winding function THD of the phase A versus the skew angle, considering the voltage drop restriction.

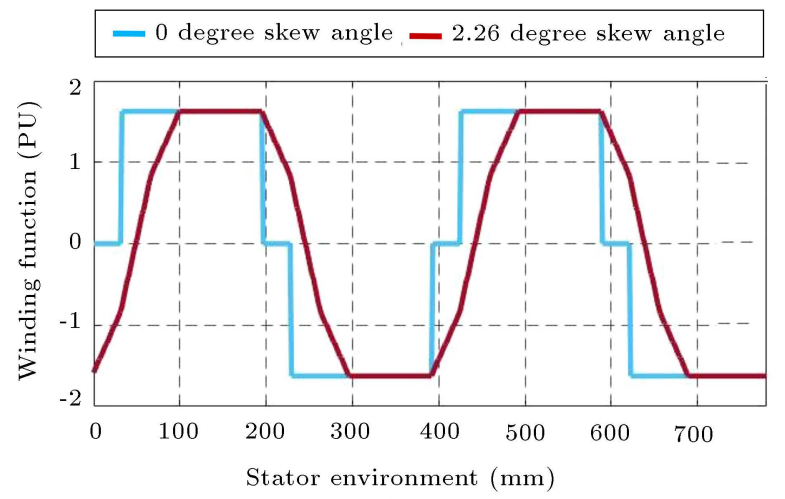

(a)

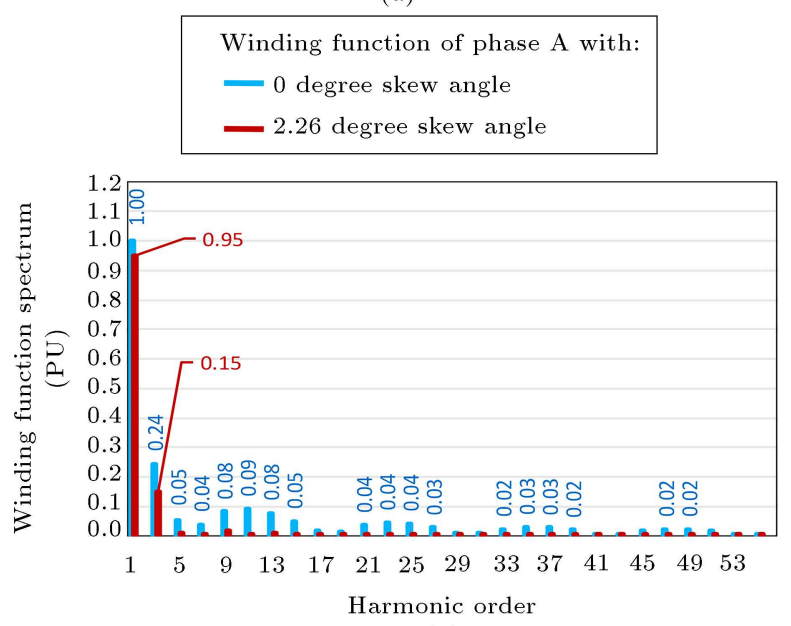

(b)

Figure 10. Winding function of phase A for $0^{\circ}$ and $2.26^{\circ}$ skew angles: (a) Distribution and (b) harmonic spectrum. All results are normalized by the fundamental harmonic value of $0^{\circ}$ skew angle.

\section{Finite Element Method (FEM)}

A 2D FEM is used in the ANSYS Maxwell software with the steady state solution type to validate the results of the analytical calculation. First, the initialdesign PMSG is simulated and the simulation results are presented in Table 2. It is clear that the simulation results are compatible with both the analytical results and experimental results from [32]. Then, the optimum generator is simulated and the simulation results are reported in Table 4, which prove the accuracy of the calculation results of the optimum design. Figures 11 and 12 show the line-to-line voltage of the optimum PMSG in both no-load and full-load conditions, respectively. In the full-load condition, the voltage THD is reduced compared to the no-load condition obviously. On the other hand, the RMS value of the output voltage is reduced in the full-load condition compared to the no-load condition because of the voltage drop across the generator phase impedance.

In the full-load condition, the flux density distribution and the flux line of the optimum PMSG are given in Figure 13 and as can be seen, saturation does not occur. In addition, the simulation results for volt-

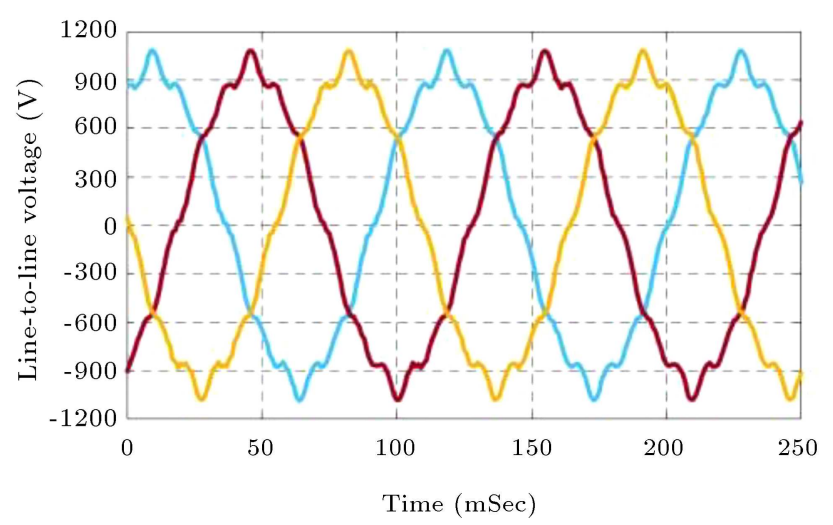

Figure 11. Line-to-line voltage of the optimized PMSG in the no-load condition with the THD value of $7.01 \%$.

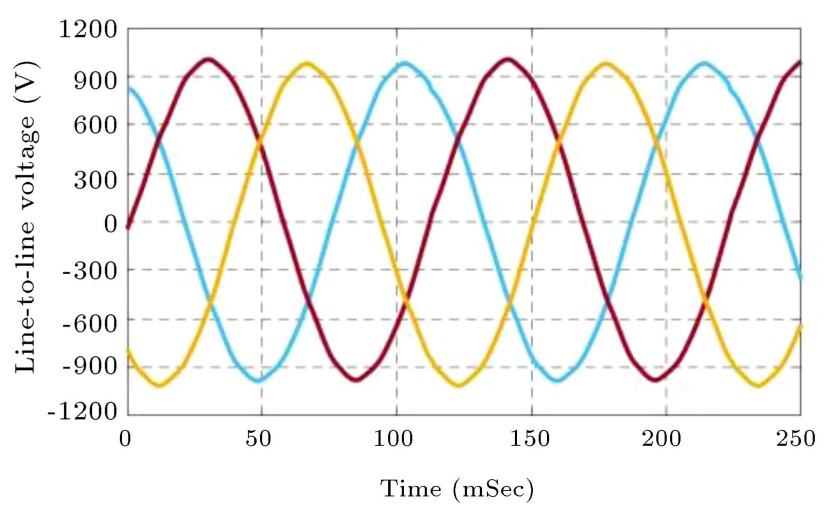

Figure 12. Line-to-line voltage of the optimized PMSG in the full-load condition with unity power factor of the load $(2.07 \%$ voltage THD and $5.94 \%$ voltage drop). 

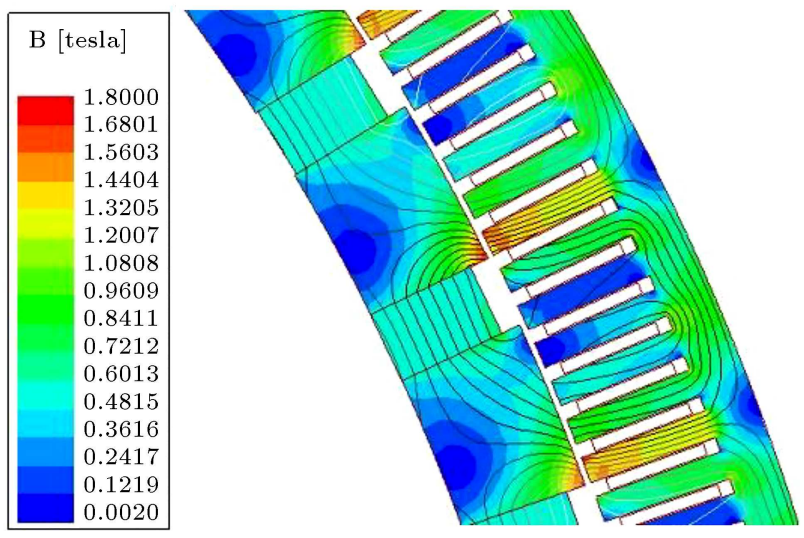

Figure 13. Flux density distribution and flux line of the rotor and the stator for the optimized PMSG in the full-load condition with unity power factor of the load.

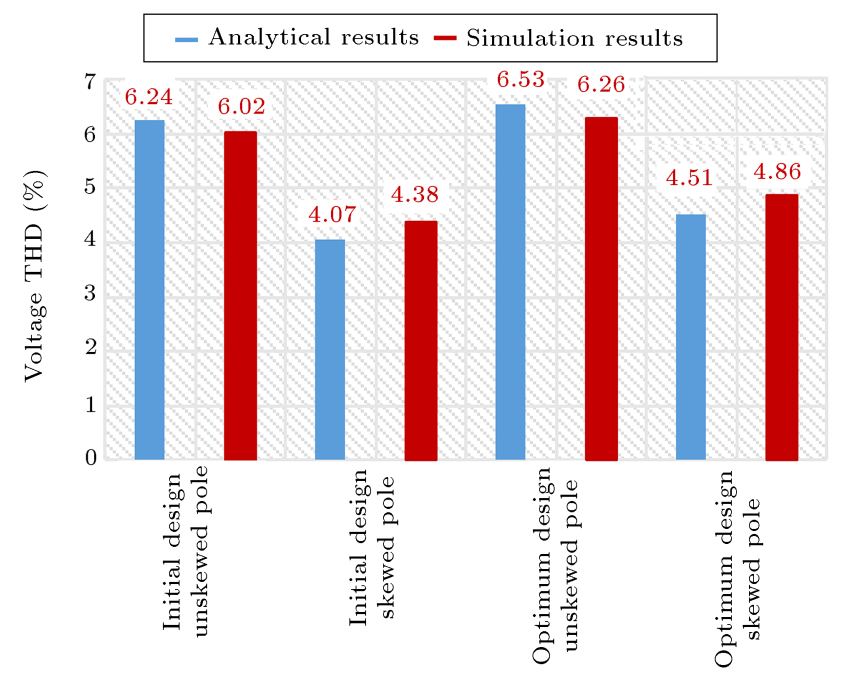

Figure 14. The output voltage THD for rough and optimum designed PMSG by using calculation and simulation results.

age THD are shown in Figure 14 to verify the accuracy of the analytical method. The simulation results are in good agreement with the calculation results for the voltage THD in both skewed and unskewed cases.

\section{Conclusion}

In this paper, a designing procedure for the largescale (1.5MW) PMSG was presented for the wind power application. A complete analytical model was presented based on the winding function method to calculate the generator performance. In this model, the effects of slot, tooth tip, and end winding leakage inductances were considered and the impacts of various losses such as copper, core, magnet, additional, friction, and windage were taken into account to present a more complete analytical model compared to the previously used model in [38].

An optimum PMSG was designed with $0.52 \%$ improved efficiency, $2.23 \%$ enhanced power factor, and $5.71 \%$ less required PM volume compared to the initial design using GA. Besides, a novel method to calculate the voltage THD was proposed based on the interaction between the stator and rotor winding functions. This method was employed to compute the optimum skew angle, which resulted in reducing $31 \%$ of the voltage THD compared to the optimum unskewed PMSG. Both the experimental results from [32] and finite element analysis were used to validate the accuracy of the presented design procedure, analytical model, optimum design, and THD calculation method for the PMSG.

\section{References}

1. Mueller, M. and Polinder, H., Electrical Drives for Direct Drive Renewable Energy Systems, Woodhead Publishing (2013).

2. Tapia, J.A., Pyrhonen, J., Puranen, J., et al. "Optimal design of large permanent magnet synchronous generators", IEEE Trans.Magn., 49(1), pp. 642-650 (2013).

3. Polikarpova, M., Ponomarev, P., Röyttä, P., et al. "Direct liquid cooling for an outer-rotor direct-drive permanent-magnet synchronous generator for wind farm applications", IET Electric Power Applications, $\mathbf{9}(8)$, pp. 523-532 (2015).

4. Wang, T. and Wang, Q. "Optimization design of a permanent magnet synchronous generator for a potential energy recovery system", IEEE Trans. Energy Convers., 27(4), pp. 856-863 (2012).

5. Eriksson, S., Solum, A., Leijon, M., et al. "Simulations and experiments on a $12 \mathrm{~kW}$ direct driven PM synchronous generator for wind power", Renewable Energy, 33(4), pp. 674-681 (2008).

6. Faiz, J., Ebrahimi, B.M., Rajabi-Sebdani, M., et al. Optimal design of permanent magnet synchronous generator for wind energy conversion considering annual energy input and magnet volume", in International Conference on Sustainable Power Generation and Supply, pp. 1-6 (2009).

7. Li, H. and Chen, Z. "Design optimization and site matching of direct-drive permanent magnet wind power generator systems", Renewable Energy, 34(4), pp. 1175-1184 (2009).

8. Bazzo, T., Kolzer, J.F., Carlson, R., et al. "Optimum design of a high-efficiency direct-drive PMSG", in IEEE Energy Conversion Congress and Exposition (ECCE), pp. 1856-1863 (2015).

9. Eriksson, S., Bernhoff, H., and Bergkvist, M. "Design of a unique direct driven PM generator adapted for a telecom tower wind turbine", Renewable Energy, 44, pp. 453-456 (2012).

10. Hsiao, C.Y., Yeh, S.N., and Hwang, J.C. "Design of high performance permanent-magnet synchronous wind generators", Energies, 7(11), pp. 7105-7124 (2014). 
11. Alshibani, S., Agelidis, V.G., and Dutta, R. "Lifetime cost assessment of permanent magnet synchronous generators for MW level wind turbines", IEEE Tran. Sustainable Energy, 5(1), pp. 10-17 (2014).

12. Laurit, S., Kallaste, A., Vaimann, T., et al. "Cost efficiency analysis of slow-speed slotless permanent magnet synchronous generator using different magnetic materials", in Electric Power Quality and Supply Reliability Conference (PQ), pp. 221-224 (2014).

13. Chebak, A., Viarouge, P., and Cros, J. "Optimal design of a high-speed slotless permanent magnet synchronous generator with soft magnetic composite stator yoke and rectifier load", Mathematics and Computers in Simulation, 81(2), pp. 239-251 (2010).

14. Kowal, D., Sergeant, P., Dupré, L., et al. "The effect of the electrical steel properties on the temperature distribution in direct-drive PM synchronous generators for $5 \mathrm{MW}$ wind turbines", IEEE Trans. Magn., 49(10), pp. 5371-5377 (2013).

15. Semken, R.S., Nutakor, C., Mikkola, A., et al. "Lightweight stator structure for a large diameter direct-drive permanent magnet synchronous generator intended for wind turbines", IET Renewable Power Generation, 9(7), pp. 711-719 (2015).

16. Zhang, F., Du, G., Wang, T., et al. "Rotor retaining sleeve design for a 1.12-MW high-speed PM machine", IEEE Trans. Ind. Appl., 51(5), pp. 3675-3685 (2015).

17. Bazzo, T., Kölzer, J., Carlson, R., et al. "Multiphysics design optimization of a permanent magnet synchronous generator", IEEE Trans. Ind. Electron., 64(12), pp. 9815-9823 (2017).

18. Lim, D., Jung, S., Yi, K., et al. "A novel sequentialstage optimization strategy for an interior permanent magnet synchronous generator design", IEEE Trans. Ind. Electron., 65(2), pp. 1781-1790 (2018).

19. Sindhya, K., Manninen, A., Miettinen, K., et al. "Design of a permanent magnet synchronous generator using interactive multiobjective optimization", IEEE Transactions on Industrial Electronics, 64(12), pp. 9776-9783 (2017).

20. Ibtissam, B., Mourad, M., Medoued, A., et al. "Multi-objective optimization design and performance evaluation of slotted Halbach PMSM using Monte Carlo method", Scientia Iranica, 25(3), pp. 1533-1544 (2018).

21. Arslan, S., Gurdal, O., and Akkaya Oy, S. "Design and optimization of tubular linear permanent-magnet generator with performance improvement using response surface methodology and multi-objective genetic algorithm", Scientia Iranica, 27(6), pp. 3053-3065 (2020).

22. Boules, N. "Two-dimensional field analysis of cylindrical machines with permanent magnet excitation", IEEE Trans. Ind. Appl., IA-20(5), pp. 1267-1277 (1984).

23. Boules, N. "Prediction of no-load flux density distribution in permanent magnet machines", IEEE Trans. Ind. Appl., IA-21(3), pp. 633-643 (1985).
24. Zou, Y. and He, J. "Comprehensive modeling, simulation and experimental validation of permanent magnet synchronous generator wind power system", in IEEE/IAS 52nd Industrial and Commercial Power Systems Technical Conference (I\&CPS), pp. 1-9 (2016).

25. Kim, C., Koo, M., Kim, J., et al. "Core loss analysis of permanent magnet synchronous generator with slotless stator", IEEE Trans. Appl. Supercond., 28(3), pp. 1-4 (2018).

26. Kuchenbecker, W.E. "Procedures to determine inductances of permanent magnet generators", IEEE Latin America Transactions, 13(8), pp. 2646-2652 (2015).

27. Rezazadeh, G., Tahami, F., and Valipour, H. "Threephase PFC rectifier with high efficiency and low cost for small PM synchronous wind generators", in 2016 7th Power Electronics and Drive Systems Technologies Conference (PEDSTC), pp. 302-307 (2016).

28. Tiwari, R. and Babu, N.R. "Fuzzy logic based MPPT for permanent magnet synchronous generator in wind energy conversion system", IFAC-PapersOnLine, 49(1), pp. 462-467 (2016).

29. Chowdhury, M.M., Haque, M.E., Saha, S., et al. "An enhanced control scheme for an IPM synchronous generator based wind turbine with MTPA trajectory and maximum power extraction", IEEE Trans. Energy Convers., 33(2), pp. 556-566 (2018).

30. Abdelrahem, M., Hackl, C.M., and Kennel, R. "Finite position set-phase locked loop for sensorless control of direct-driven permanent-magnet synchronous generators", IEEE Trans. Power Electron., 33(4), pp. 30973105 (2018).

31. Rezazadeh, G., Vaschetto, S., Tahami, F., et al. "Analysis of six-phase induction motor with distributed and concentrated windings by using the winding Function Method", in XIII International Conference on Electrical Machines (ICEM), pp. 2423-2429 (2018).

32. Bywaters, G., Northern Power NW 1500 Direct-Drive Generator, Northern Power Systems, Inc. (2006).

33. Alemi-Rostami, M., Alipour-Sarabi, M., Rezazadeh, G., et al. "Design optimization of a double-stage resolver", IEEE Transactions on Vehicular Technology, 68(6), pp. 5407-5415 (2019).

34. Boldea, I. and Nasar, S.A., The Induction Machine Handbook, CRC Press (2010).

35. Tutelea, L. and Boldea, I. "Surface permanent magnet synchronous motor optimization design: Hooke Jeeves method versus genetic algorithms", in 2010 IEEE International Symposium on Industrial Electronics, pp. 1504-1509 (2010).

36. Grauers, A. "Design of direct-driven permanentmagnet generators for wind turbines", Ph.D. Thesis, School of Electrical and Computer Engineering, Chalmers University of Technology, Sweden (1996).

37. Ghasemian, M., Tahami, F., and Rezazadeh, G. "A comparative analysis of permanent magnet flux reversal generators with distributed and concentrated 
winding", in IECON - 43rd Annual Conference of the IEEE Industrial Electronics Society, pp. 1657-1661 (2017).

38. Raziee, S.M., Misir, O., and Ponick, B. "Winding function approach for winding analysis", IEEE Trans. Magn., 53(10), pp. 1-9 (2017).

39. Alipour-Sarabi, R., Nasiri-Gheidari, Z., Tootoonchian, F., et al. "Improved winding proposal for wound rotor resolver using genetic algorithm and winding function approach", IEEE Trans. Ind. Electron., 66(2), pp. 1325-1334 (2019).

40. Rezazadeh, G., Ghasemian, M., and Nasiri-Gheidari, Z. "Ultra low vibration and low acoustic noise multistage switched reluctance machine", in 9th Annual Power Electronics, Drives Systems and Technologies Conference (PEDSTC), pp. 271-276 (2018).

\section{Biographies}

Mehdi Alemi-Rostami was born in Behashahr, Iran, 1980. He received the BSc degree from Gilan University, Gilan, Iran, 1998 as well as MS and $\mathrm{PhD}$ degrees from Iran University of Science and Technology, Tehran, Iran in 2000 and 2011, respectively, all in Power Electronics. He is currently an Assistant Professor with the Aerospace Research Institute (ARI), Ministry of Science, Research, and Technology, Tehran, Iran.

Ghasem Rezazadeh was born in Freydoonkenar, Iran in 1990. He received the BS degree in Electrical Engineering from Shahid Beheshti University in 2012. In 2014, he received his MSc degree from Sharif University of Technology, Tehran, Iran. He is currently striving to achieve a $\mathrm{PhD}$ degree from a co-supervision between Sharif University of Technology and the University of Picardie "Jules Verne", Amiens, France. His research interests include electrical machine design, modeling, and drive.

Ramin Alipour-Sarabi was born in Sarab, Iran in 1989. He received the BSc degree from Iran University of Science and Technology, Tehran, Iran in 2012 and MSc degree from the Sharif University of Technology, Tehran in 2014, where he is currently trying to obtain a $\mathrm{PhD}$ degree all in Electrical Engineering. His current research interests include power electronics and design, optimization, and performance analysis of electrical machines and electromagnetic sensors.

Farzad Tahami received the BS degree in Electrical Engineering from Ferdowsi University of Mashhad, Mashhad, Iran in 1991 and the MS and PhD degrees in Electrical Engineering from the University of Tehran, Tehran, Iran in 1993 and 2003, respectively. From the year 1991 to 2004, he was with R\&D Department of Jovain Electrical Machines Corporation (JEMCO), Iran. In 2004, he joined Sharif University of Technology, Tehran, Iran, where he is currently an Associate Professor. Since 2007, he has been the Chairman of the Technical Committee of Rotating Machinery, The Iranian National Electrotechnical Committee (INEC). Dr. Tahami is a Member of the Board of Directors and the Chairman of the Education Committee of the Power Electronics Society of Iran (PESI). His current research interests include electric motor drives, modeling and control of power electronic converters, soft switching, resonant converters, and wireless power transfer. 